\title{
UK unveils patient-centred electronic health strategy
}

$\mathrm{C}$ ompleting a full retreat from an e-health strategy based on centralized national records, the government of the United Kingdom has unveiled a 10-year blueprint that aims to put the "power of information" in the hands of patients.

Among pledges is a plan to compel all general practices to offer patients electronic access to their health records, electronic appointment scheduling, electronic renewal of prescriptions and electronic "communication with the practice" by 2015 .

It's part of a focus on patient-centred innovations, UK Secretary of State for Health Andrew Lansley stated in the forward to The power of information: Putting all of us in control of the health and care information we need (www .dh.gov.uk/prod_consum_dh/groups/dh _digitalassets/@dh/@en/documents /digitalasset/dh_134205.pdf).
While there's a need for government to set standards "that allow different systems to communicate with each other and to enable us to access the trusted information and services we need ... in some areas, progress will be greater with the centre 'getting out of the way' so that local organisations, system developers, information specialists, voluntary sector organisations and others can innovate," Lansley wrote.

Much as with Canada Health Infoway's electronic health records blueprint, the UK's former $£ 13$ billion strategy was long excoriated as neither practical nor achievable (www.cmaj.ca/lookup /doi/10.1503/cmaj.109-4001). The UK's Public Accounts Committee deemed it as "beyond the capacity of the Department to deliver" (www.publications .parliament.uk/pa/cm201012/cmselect /cmpubacc/1070/107002.htm), while the UK Public Administration Select
Committee concluded the government essentially does not know how to develop information technology systems or judiciously shop for either hardware or software (www.publications .parliament.uk/pa/cm201012/cmselect /cmpubadm/715/715i.pdf).

In September, 2011, the Department of Health announced that it would "accelerate" the dismantling of the National Health Services' National Programme for IT [Information Technology], which has been plagued by scandals involving massive contracts with IT corporations (http://mediacentre.dh .gov.uk/2011/09/22/dismantling-the-nhs -national-programme-for-it/), while in March, Lansley announced that Connecting for Health, the agency which ran the program, would no longer exist in April 2013. "In the past doctors and nurses have had to bend over backwards to fit in with the needs of the systems

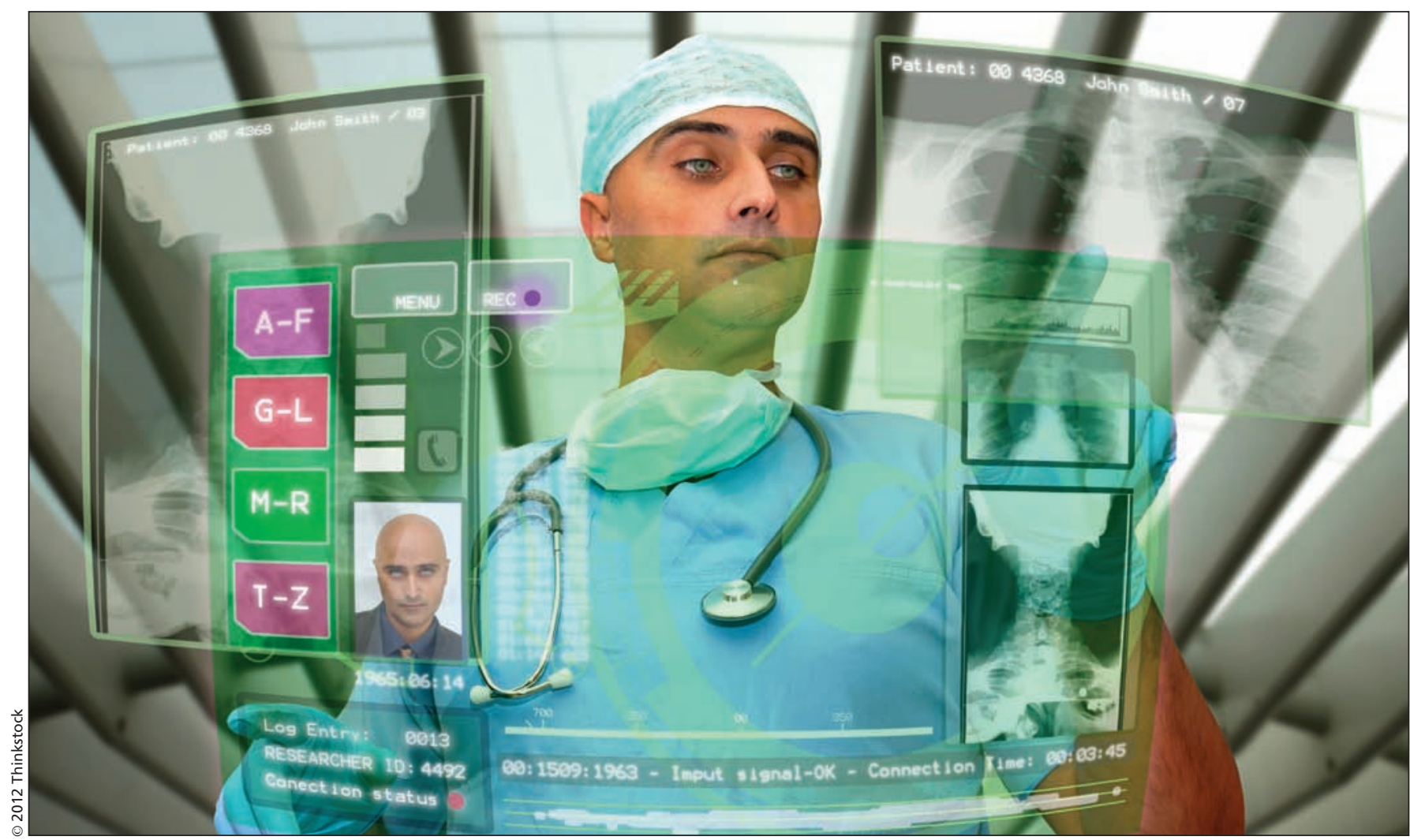

The United Kingdom's new e-health strategy proposes that a physician be able to access a patient's relevant health records "online, simply, securely and all in one place." 
introduced to their workplaces. They were shackled with rigid, expensive IT contracts that failed to deliver as intended. We are now putting local clinicians in the driving seat, able to reap the benefits of the explosion in information and technology which is re-shaping the world beyond" the National Health Service, he stated in a press release (http://mediacentre.dh.gov.uk/2012/03/08 /shifting-power-to-the-local-nhs-a-new -way-for-nhs-it/).

Along with its vow to connect clinicians and patients through a simple, user-friendly electronic portal to be provided by the government in 2013 , the new plan focuses on a drive for information transparency. It decrees that each patient's National Health Service number "will be used to connect our records across the whole system as we move between services. This, as well as professionals being able to access relevant records online, simply, securely and all in one place (for example via 'clinical portals'), will enable more joined-up care. By 2014, pilots for the use of integrated barcode medication administration systems in care homes will inform future plans for implementation across England."

Transparency will be further served through the publication of all "national clinical audit data by clinical team from April 2012, [while] all clinical outcomes data will be put into the public domain by 2015."

In the interests of utilizing that data to drive "improvements in care, enterprise and innovation," it will be made available, at a fee to cover the cost of "the linking process," commencing in September 2012.

By making information about clinical care available to the public, the initiative will enable them to benchmark services and "help us see and compare the quality of care provided by local services, to help us choose which best meets our needs," the plan adds.

The plan's framers also argued that the program will serve to leave Britain poised to "play a prominent part in a global industry which will deliver economic growth."

To achieve such objectives, it will be necessary for informatics development to be woven into health education and training programs, and for health administrators to identify and hire persons responsible for "organizing information in support of better care." But at the local level, it will be necessary to appoint a "a senior clinician or care professional responsible for taking the lead in ensuring that information is organized and utilized effectively in support of better patient care."

Overall, though, the strategy does not articulate in any detail what other specific measures will be necessary to achieve its many objectives. But that was deliberate, its framers noted. "Unlike previous information strategies, this strategy does not reinvent large-scale information systems or set down detailed mechanisms for delivery. Rather, it provides a framework and a route map to lead a transformation in the way information is collected and used. It takes the needs of us as patients, carers, users of care services and citizens as the key driver for change. It provides the infrastructure to support the things that need to be done system-wide but - recognising that information technology is always advancing — it promotes flexibility and local innovation."

As part of the plan to require all general practices to be wired by 2015 , the government asked the Royal College of General Practitioners to "lead development of a plan, policy and procedures to support patient access and engagement with their GP records."

The ultimate burden on physicians may be substantial. As the plan notes, they will be "encouraged to ensure safer, quicker, more efficient care by transferring electronically all correspondence about patients and service users, includ- ing referrals, discharge summaries, medication details, assessments (including CAF [Common Assessment Framework]), outcomes and letters, between professionals and services. These data transfers should be coded and structured as far as possible, in particular in respect of discharge diagnoses. This will enable increasingly automated derivation of national data sets, national statistics (such as Hospital Episode Statistics) and national outcome metrics."

Another detail absent from the plan is any indication of the level of funding that will be provided to meet its requirements. But it does recognize "the need for central funding to be available" and indicates a capital fund is being developed for the first two years of its implementation.

It will be impossible to accomplish without substantial new investments, says Veena Raleigh, senior fellow at the King's Fund, a health system think tank in London. While the decision to focus on clinician-patient interaction and information transparency "is the right way forward, ... this is a big mountain to climb on skimpy rations, and progress is likely to be patchy, incremental and determined by local buy-in."

But not all UK e-health analysts believe money will be needed to drive innovation. Some, like Carl Reynolds, clinical advisor for the National Patient Safety Agency in London, argue that the health care system will actually save money by utilizing open-source software, rather than proprietary products. "The era of getting locked into massive contracts may be over."

Similar approaches are need in Canada, argues Sholom Glouberman, president of the Patients' Association of Canada, and a member of the clinician council for Canada Health Infoway. "We have to start thinking about enhancing our strategy in the same way." - Paul Christopher Webster, Toronto, Ont.

CMAJ 2012. DOI:10.1503/cmaj.109-4233 